\title{
Experiment on Chloride Ion Content of Concrete Structure in Coastal Salt-fog Area
}

\author{
Ming NIE ${ }^{1, ~ a}$, Hongjia HUANG ${ }^{2, ~ b}$, Yuan DAI ${ }^{1, ~ c}$, Wensheng $\mathrm{LI}^{1, \mathrm{~d}}$, \\ Pengxiao JIANG ${ }^{2, ~ e ~ a n d ~ W e i j u n ~} \mathrm{YANG}^{2, \mathrm{f}}$ \\ ${ }^{1}$ Electric Power Research Institute of Guangdong Power Grid Co. Ltd., Guangzhou 510080, China; \\ ${ }^{2}$ Changsha University of Science and Technology, Changsha, Hunan, 410114, China;

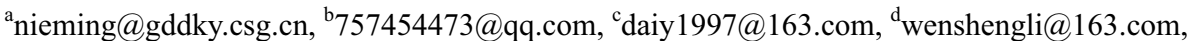 \\ e283861901@qq.com, ${ }^{\mathrm{f}} \mathrm{mgbyrh} @ 163 . c o m$
}

\begin{abstract}
This paper chose the south-east coastal salt-fog area Shantou to carry out the experiment study on chloride ion content of concrete structure, through the chloride ion content field test on reinforced concrete structure in Shantou, respectively for the slat-fog atmosphere zone and the splash zone in marine environment, discuss the corrosion by chloride ion of long-time existing concrete structure.And then measure the chloride ion content of concrete cover in different depth, and determine the chloride ion diffusion model in different conditions concrete through comparative analysis. The result of study, can be used in directing the selection of design scheme for building in planning, and also it will help predict the corrosion time of reinforcement inside the concrete on different positions for existing structure.
\end{abstract}

\section{Introduction}

The monthly average value of the salt-fog amount in south-eastern area of China is between 0.1069 and $0.7425 \mathrm{mg} / \mathrm{m}^{2}$, while the annual average value is between 0.148 and $0.480 \mathrm{mg} / \mathrm{m}^{2}$. The maximum differs from the minimum by an order of magnitude. On account of a large number of huge concrete infrastructures, such as port, substation, sea-crossing bridge and so on, were built in coastal areas, the erosion of chlorine ion in the marine environment work on concrete structures is more gravity. That would directly led structures destruction and performance degradation of coastal reinforced concrete(Fig.1). Once the chloride amount exceeds a certain limited point, the deactivation state of steel surface would be break, that would bring about the corrosion of steel which could make the structure bearing capacity drops, and at last cause structural failure. Therefore, enough attention should be caught for the chloride ion concentration of concrete structure at coastal salt-fog areas. It is very significant for the research.

\footnotetext{
* Corresponding author:nieming@gddky.csg.cn
} 

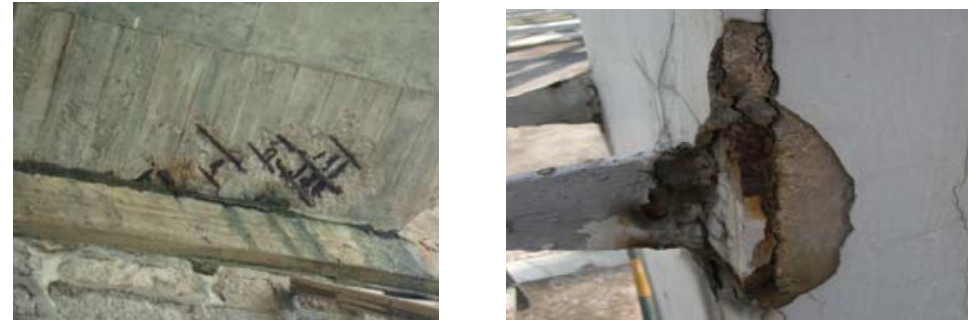

Fig.1 Seriously Protective layer peeling and reinforcement corrosion concrete structure at coastal salt-fog area

(Bridges, substation)

\section{Experiment Scheme}

This paper chose selects the southeast coastal salt-fog area Shantou to carry out the experimental study of concrete structure chlorine ion concentration.Starting from the actual situation of Shantou area(Table 1), through investigation and sample of reinforced concrete structures at Shantou area, discussed the chlorine ion erosion situation of concrete structure which service for a long time, and determinate the chlorine ion concentration of each layer of concrete. Through comparative analysis, determining the chlorine ion diffusion model under different concrete conditions.

Table 1 Sampling Environment Situation

\begin{tabular}{|c|c|c|}
\hline $\begin{array}{l}\text { Samplin } \\
\text { g Point } \\
\text { Code }\end{array}$ & Sampling Point Location & $\begin{array}{c}\text { Concrete Strength and Service Time at } \\
\text { Sampling Point }\end{array}$ \\
\hline $\mathrm{a}$ & $\begin{array}{l}\text { Shantou car and ferry stone } \\
\text { dock }\end{array}$ & $\begin{array}{l}\text { concrete strength is } \mathrm{C} 30 \text {, service time is } \\
\qquad 15 \text { years }\end{array}$ \\
\hline $\mathrm{b}$ & $\begin{array}{l}\text { Laichang car and ferry Laiwu } \\
\text { dock }\end{array}$ & $\begin{array}{l}\text { Established in 1992, concrete strength is } \\
\qquad \text { C20 }\end{array}$ \\
\hline $\mathrm{c}$ & $\begin{array}{c}\text { auxiliary bridge of South } \\
\text { Australia bridge }\end{array}$ & $\begin{array}{c}\text { concrete strength is } \mathrm{C} 30 \text {, service time is } 5 \\
\text { years }\end{array}$ \\
\hline d & $\begin{array}{c}\text { Shantou harbor bureau yard } \\
\text { dock }\end{array}$ & $\begin{array}{l}\text { Established in 1994, concrete strength is } \\
\qquad \text { C30 }\end{array}$ \\
\hline $\mathrm{e}$ & Haimen bridge. & $\begin{array}{l}\text { Established in 1995, concrete strength is } \\
\qquad \text { C25 }\end{array}$ \\
\hline
\end{tabular}

Marine environment can be divided into four different zones, that is, salt-fog atmosphere zone, splash zone, tidal-range zone and whole sea-soaked zone. Even if reinforced concrete structure is situated in the same marine environment, in marine different zones, the corrosive degrees will be different.

The experiment chose the most typical zones, namely, the splash zone and the salt-fog atmosphere zone. Among them, as to concrete structure in the splash zone, we chose the 
samples from different heights of the sea-level; as to the concrete structure in the salt-fog atmosphere zone, there exists different relative positions between the concrete surface and the sea level. For instance, the frontage of a rectangle faces the sea directly while its other three sides face the sea by side or with its back. Therefore, in salt-fog atmosphere zone, we can take samples from windward side, leeward side and profile.(Fig.2)

The experiment adopt the sampling method of electric impact drill drilling step by step, which advantage is simple and quickly operation. However there are some shortcomings of the method: 1 , the influence of sea wind cause difficulty of powder collection; 2 , the drilling depth is difficult to control due to the huge impact force; 3 , the graduation of powder is heterogeneity; 4, the drill point is not an ideal cylinder because of the cone-shaped drill, that would bring about a amount of error; 5 , porous drilling is required because of the little quantity of every-time powder taking.
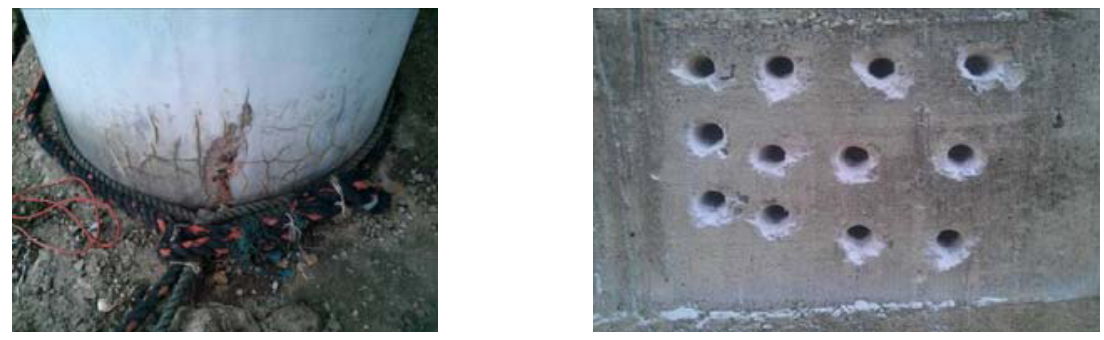

Fig.2 Haimen bridge piers in salt-fog atmosphere zone

Fig.3 Impact drill

According to the above points, the following measures should be taken as far as possible: 1 , the dynamics must be under controlled, prevent excessively drill depth; 2 , considering the influence of drill, confirm the barycenter of drilling; 3, collecting all the powder as far as possible; 4, At least six separately areas should be taken to collecting the powder, that can guarantee not only the amount of powder, but also the uniformity graduation of powder.

\section{Chlorine Ion Concentration Measurement}

The experiment adopt the method of electric impact drill drilling to divide the concrete into several layers, and then sample respectively. The diameter of drilling is $20 \mathrm{~mm}$, the distance of layered drilling depth to the surface are $0 \mathrm{~mm} 、 2.5 \mathrm{~mm} 、 7.5 \mathrm{~mm} 、 12.5 \mathrm{~mm}$ 、 $17.5 \mathrm{~mm} 、 22.5 \mathrm{~mm}$ and $27.5 \mathrm{~mm}$. Using the square-opening sieve which sieve diameter is $0.075 \mathrm{~mm}$ to remove coarse particle. The text carried out in accordance with the standard of standard for test methods of long-term performance and durability of ordinary concrete GBT50082. In order to prevent the influence caused by chloride from top-water, the experiment adopt deionized water compound solution with the rest powder, after 24 hour's uninterrupted stirring in magnetic stirrer, measure the water-solubility chloride ion concentration by NJCL-H quick chloride ion concentration apparatus(Fig.5) . 


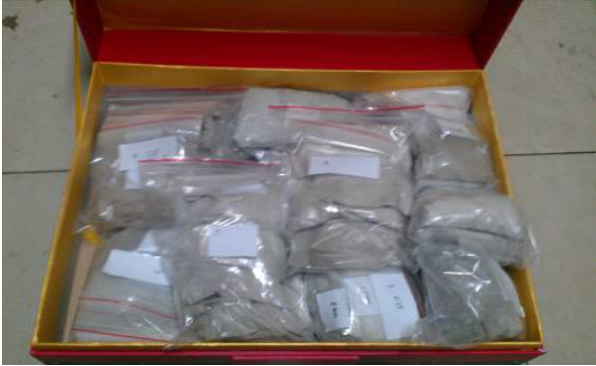

Fig.4 NJCL-H quick chloride ion concentration apparatus

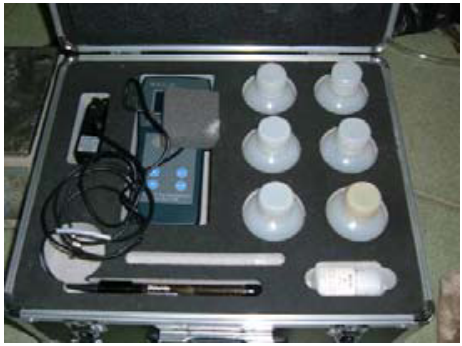

Fig.5 Drilling for powder samples

In order to improve the test precision, take three groups of powder for each depth of every individual specimen, and each group samples measured three times. The calculation formula of chlorine ion concentration inside the concrete is:

$$
X_{c l-}=35.45 c \bullet v / 10 m
$$

In the formula:

$\mathrm{X}_{\mathrm{cl}-}-$ Concrete chloride ion concentration percentage;

$\mathrm{c}-$ - chloride ion concentration measured by quick chloride ion concentration apparatus;

$\mathrm{v}$ - - liquid volume of aqueous solution composed with powder;

$\mathrm{m}$ - - the quality of concrete powder(g).

Calculate the detection water-solubility chloride ion concentration by formula(1), the result shown as Table 2 .

Table 2 Chloride Ion Concentration Of Each Depth Concrete

\begin{tabular}{|c|c|c|c|c|c|c|c|c|c|c|}
\hline \multirow{2}{*}{ 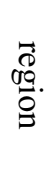 } & \multirow{2}{*}{$\begin{array}{c}\text { Sampl } \\
\text { ing } \\
\text { Point }\end{array}$} & \multicolumn{7}{|c|}{ Penetration Depth(mm) } & \multirow{2}{*}{\multicolumn{2}{|c|}{ Remarks }} \\
\hline & & 0 & 2.5 & 7.5 & 12.5 & 17.5 & 22.5 & 27.5 & & \\
\hline \multirow{5}{*}{ 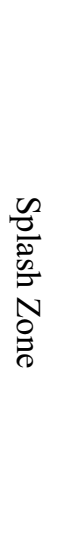 } & a1 & $\begin{array}{c}0.68 \\
86\end{array}$ & $\begin{array}{c}0.51 \\
61\end{array}$ & $\begin{array}{c}0.35 \\
58\end{array}$ & $\begin{array}{c}0.30 \\
16\end{array}$ & $\begin{array}{c}0.28 \\
25\end{array}$ & $\begin{array}{c}0.26 \\
56\end{array}$ & $\begin{array}{c}0.24 \\
71\end{array}$ & \multirow{5}{*}{$\begin{array}{l}\text { eleva } \\
\text { tion } \\
\text { from } \\
\text { the } \\
\text { sea } \\
\text { level } \\
\text { (m) }\end{array}$} & 0.5 \\
\hline & $\mathrm{a} 2$ & $\begin{array}{c}0.69 \\
61\end{array}$ & $\begin{array}{c}0.53 \\
08\end{array}$ & $\begin{array}{c}0.36 \\
28\end{array}$ & $\begin{array}{c}0.31 \\
38\end{array}$ & $\begin{array}{c}0.29 \\
47\end{array}$ & $\begin{array}{c}0.27 \\
15\end{array}$ & $\begin{array}{c}0.25 \\
65\end{array}$ & & 0.8 \\
\hline & a3 & $\begin{array}{c}0.67 \\
40\end{array}$ & $\begin{array}{c}0.49 \\
25\end{array}$ & $\begin{array}{c}0.33 \\
70\end{array}$ & $\begin{array}{c}0.28 \\
59\end{array}$ & $\begin{array}{c}0.26 \\
46\end{array}$ & $\begin{array}{c}0.25 \\
35\end{array}$ & $\begin{array}{c}0.23 \\
57\end{array}$ & & 1.0 \\
\hline & b1 & $\begin{array}{c}0.75 \\
14\end{array}$ & $\begin{array}{c}0.57 \\
91\end{array}$ & $\begin{array}{c}0.41 \\
08\end{array}$ & $\begin{array}{c}0.34 \\
54\end{array}$ & $\begin{array}{c}0.31 \\
88\end{array}$ & $\begin{array}{c}0.27 \\
15\end{array}$ & $\begin{array}{c}0.25 \\
73\end{array}$ & & 0.5 \\
\hline & b2 & 0.76 & 0.59 & 0.43 & 0.36 & 0.32 & 0.28 & 0.26 & & 0.8 \\
\hline
\end{tabular}




\begin{tabular}{|c|c|c|c|c|c|c|c|c|c|}
\hline & & 37 & 58 & 49 & 29 & 06 & 49 & 19 & \multirow{3}{*}{1.0} \\
\hline & \multirow{2}{*}{ b3 } & 0.73 & 0.56 & 0.39 & 0.32 & 0.29 & 0.25 & 0.24 & \\
\hline & & 81 & 62 & 13 & 15 & 42 & 85 & 42 & \\
\hline & \multirow{2}{*}{$\mathrm{c} 1$} & 0.19 & 0.13 & 0.10 & 0.07 & 0.05 & 0.04 & 0.04 & \multirow{2}{*}{0.5} \\
\hline & & 20 & 85 & 83 & 74 & 82 & 66 & 07 & \\
\hline & \multirow{2}{*}{ c2 } & 0.20 & 0.15 & 0.11 & 0.08 & 0.06 & 0.04 & 0.04 & \multirow{2}{*}{0.8} \\
\hline & & 14 & 78 & 86 & 40 & 01 & 87 & 14 & \\
\hline & \multirow{2}{*}{ c3 } & 0.19 & 0.13 & 0.10 & 0.07 & 0.05 & 0.04 & 0.03 & \multirow{2}{*}{1.0} \\
\hline & & 70 & 53 & 55 & 03 & 14 & 21 & 92 & \\
\hline & \multirow{2}{*}{$\mathrm{d} 1$} & 0.70 & 0.53 & 0.38 & 0.32 & 0.30 & 0.26 & 0.25 & \multirow{2}{*}{0.5} \\
\hline & & 23 & 29 & 66 & 90 & 49 & 21 & 04 & \\
\hline & \multirow{2}{*}{$\mathrm{d} 2$} & 0.72 & 0.55 & 0.40 & 0.34 & 0.31 & 0.27 & 0.25 & \multirow{2}{*}{0.8} \\
\hline & & 14 & 29 & 14 & 90 & 81 & 74 & 82 & \\
\hline & \multirow{2}{*}{ d3 } & 0.68 & 0.51 & 0.36 & 0.31 & 0.28 & 0.24 & 0.23 & \multirow{2}{*}{1.0} \\
\hline & & 44 & 52 & 49 & 66 & 05 & 35 & 13 & \\
\hline & \multirow{2}{*}{ e1 } & 0.69 & 0.52 & 0.37 & 0.31 & 0.29 & 0.25 & 0.24 & \multirow{2}{*}{0.5} \\
\hline & & 26 & 92 & 21 & 77 & 12 & 64 & 81 & \\
\hline & \multirow{2}{*}{ e2 } & 0.71 & 0.54 & 0.39 & 0.33 & 0.30 & 0.26 & 0.25 & \multirow{2}{*}{0.8} \\
\hline & & 36 & 17 & 23 & 18 & 46 & 81 & 29 & \\
\hline & \multirow{2}{*}{ e3 } & 0.67 & 0.51 & 0.35 & 0.30 & 0.27 & 0.23 & 0.22 & \\
\hline & & 82 & 21 & 84 & 08 & 46 & 92 & 47 & 1.0 \\
\hline \multirow{11}{*}{ 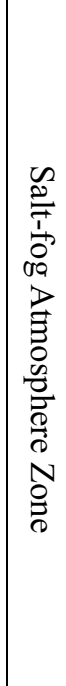 } & \multirow{2}{*}{ a4 } & 0.50 & 0.38 & 0.30 & 0.24 & 0.21 & 0.20 & 0.19 & \multirow{2}{*}{$\begin{array}{c}\text { windward } \\
\text { side }\end{array}$} \\
\hline & & 35 & 21 & 94 & 05 & 70 & 53 & 31 & \\
\hline & \multirow{2}{*}{ a5 } & 0.48 & 0.35 & 0.28 & 0.22 & 0.20 & 0.18 & 0.17 & \multirow{2}{*}{ profile } \\
\hline & & 51 & 97 & 71 & 53 & 48 & 90 & 18 & \\
\hline & \multirow{2}{*}{ a6 } & 0.43 & 0.30 & 0.23 & 0.17 & 0.15 & 0.13 & 0.12 & \multirow{2}{*}{$\begin{array}{c}\text { leeward } \\
\text { side }\end{array}$} \\
\hline & & 22 & 55 & 06 & 79 & 49 & 53 & 74 & \\
\hline & b4 & 0.55 & 0.42 & 0.34 & 0.27 & 0.24 & 0.22 & 0.21 & windward \\
\hline & & 12 & 08 & 08 & 64 & 51 & 90 & 86 & side \\
\hline & b5 & 0.52 & 0.39 & 0.31 & 0.26 & 0.23 & 0.21 & 0.20 & \\
\hline & & 26 & 33 & 11 & 98 & 43 & 92 & 55 & \\
\hline & b6 & 0.47 & 0.34 & 0.27 & 0.21 & 0.18 & 0.17 & 0.16 & leeward \\
\hline
\end{tabular}




\begin{tabular}{|c|c|c|c|c|c|c|c|c|}
\hline & 55 & 86 & 33 & 28 & 10 & 36 & 60 & side \\
\hline \multirow{2}{*}{$\mathrm{c} 4$} & 0.15 & 0.12 & 0.09 & 0.07 & 0.05 & 0.04 & 0.03 & windward \\
\hline & 49 & 95 & 12 & 11 & 46 & 08 & 58 & side \\
\hline \multirow{2}{*}{$\mathrm{c} 5$} & 0.13 & 0.11 & 0.08 & 0.06 & 0.05 & 0.03 & 0.03 & \multirow{2}{*}{ profile } \\
\hline & 92 & 87 & 79 & 71 & 07 & 77 & 31 & \\
\hline \multirow{2}{*}{ c6 } & 0.10 & 0.08 & 0.06 & 0.04 & 0.03 & 0.02 & 0.02 & leeward \\
\hline & 31 & 51 & 36 & 48 & 61 & 33 & 15 & side \\
\hline \multirow{2}{*}{$\mathrm{d} 4$} & 0.52 & 0.39 & 0.31 & 0.25 & 0.22 & 0.20 & 0.20 & windward \\
\hline & 14 & 78 & 86 & 40 & 01 & 87 & 50 & side \\
\hline \multirow{2}{*}{$\mathrm{d} 5$} & 0.49 & 0.36 & 0.28 & 0.23 & 0.20 & 0.19 & 0.18 & \multirow{2}{*}{ profile } \\
\hline & 22 & 61 & 87 & 92 & 84 & 01 & 81 & \\
\hline \multirow{2}{*}{ d6 } & 0.45 & 0.32 & 0.25 & 0.19 & 0.16 & 0.15 & 0.14 & leeward \\
\hline & 77 & 12 & 90 & 52 & 51 & 43 & 23 & side \\
\hline \multirow{2}{*}{ e4 } & 0.52 & 0.40 & 0.32 & 0.24 & 0.22 & 0.20 & 0.19 & windward \\
\hline & 54 & 05 & 29 & 71 & 62 & 64 & 88 & side \\
\hline \multirow{2}{*}{ e5 } & 0.49 & 0.37 & 0.29 & 0.21 & 0.20 & 0.19 & 0.18 & \multirow{2}{*}{ profile } \\
\hline & 85 & 06 & 69 & 91 & 78 & 54 & 28 & \\
\hline \multirow{2}{*}{ e6 } & 0.45 & 0.33 & 0.25 & 0.20 & 0.17 & 0.15 & 0.14 & leeward \\
\hline & 47 & 90 & 14 & 16 & 40 & 87 & 27 & side \\
\hline
\end{tabular}

\section{Chloride Ion Concentration Measured Results Analysis}

According to the test data in Table 2, drawing the relation graph between chlorine ion concentration and penetration depth under different conditions in Shantou area marine environment(Fig.6 7). 


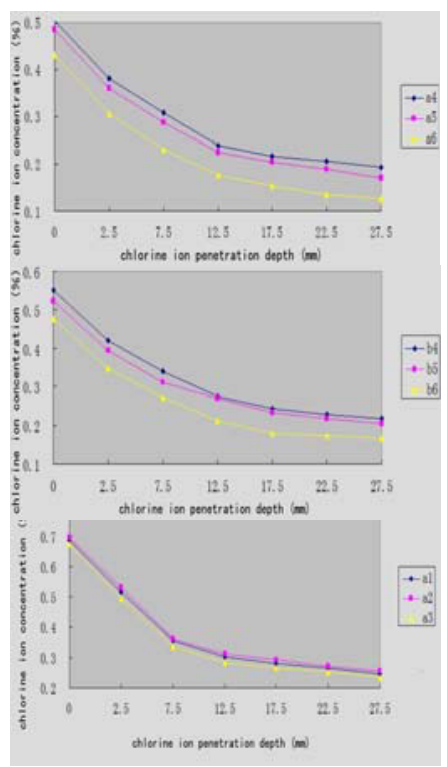

Fig.6 Relation graph between chlorine ion concentration

and penetration depth at the same structure but different

elevation in splash zone

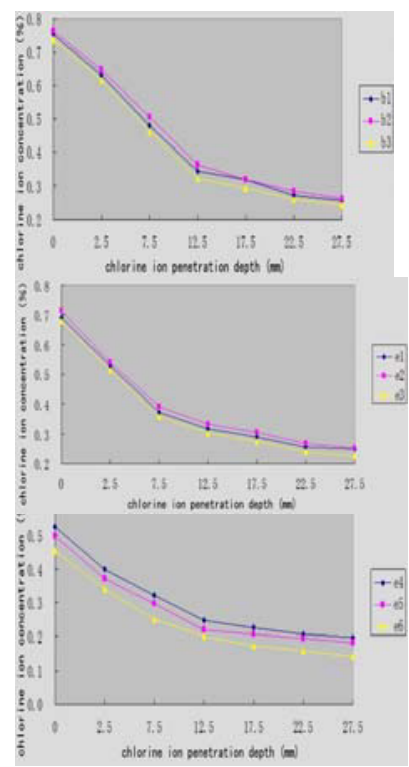

Fig.7 Relation graph between chlorine ion

concentration and penetration depth at the

same structure but different position in

salt-fog atmosphere zone

It can be seen from the Fig.6 and Fig.7 that, in Shantou area marine environment, no matter in splash zone or salt-fog atmosphere zone, the each depth chloride ion concentration of reinforced concrete structure diminishing gradually with the deepen of invasion depth. Also it can been seen form the picture that there are three different development trend of concrete chloride ion concentration at Shantou area: at the range that the distance from concrete surface is $0 \sim 12.5 \mathrm{~mm}$, with distance increase the chloride ion concentration reduce quickly and the reduction amplitude is significant; at the range that the distance from concrete surface is $12.5 \sim 22.5 \mathrm{~mm}$, with distance increase the chloride ion concentration reduction amplitude becoming mild; at the range that the distance from concrete surface exceed $22.5 \mathrm{~mm}$, chloride ion concentration gradually become stable, almost not influenced by depth change. The reason why chloride ion concentration is presented like that is chloride ion could invasion the surface of concrete structure through a variety of different ways, so the chloride ion abundant gather at the concrete surface, however as the invasion of chloride ion, a large number of chloride ion has been chemical binding and physical adsorption, that led to chloride ion concentration reduce significantly. In the process of chloride ion diffuse to the inside concrete, due to the solidification of concrete combined with chloride ion tends to saturation, the chloride ion concentration gradually become stable.

It can be seen from the Fig.6, the Shantou area concrete structure located in splash zone, the chloride ion concentration changes with the different elevation from the sea level: as the increase of elevation, the chloride ion concentration first increased to a top point and then began to gradually decrease, present the parabolic trend.It can be seen from the Fig.7, the concrete structure located in salt-fog atmosphere zone, and the sample a4 was taken from the windward side, a5 was taken from the profile, a6 was taken from the leeward side, chloride ion concentration from different sample has difference because of the different sample taken position. Visible, the different relative position between concrete surface and 
sea surface has conspicuous influence on concrete interior chloride ion concentration.

According to the test data in Table 2, reference to the service time of concrete structures, drawing the relation graph between chlorine ion concentration and penetration depth under different service time in salt-fog atmosphere zone and splash zone(Fig.8 9).

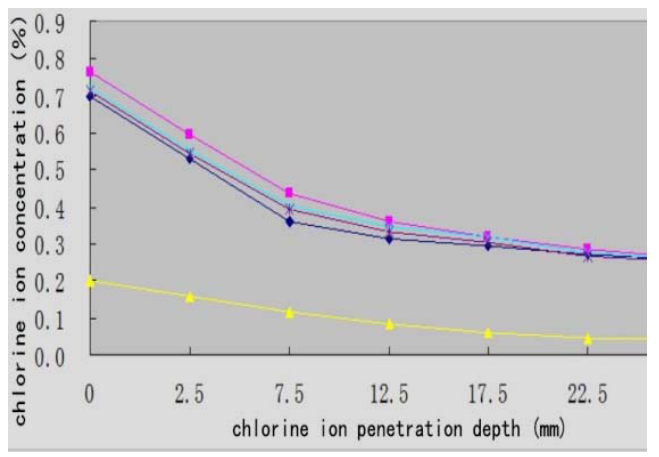

Fig.8 Relation graph between chlorine ion

concentration and penetration depth under different service time in splash zone

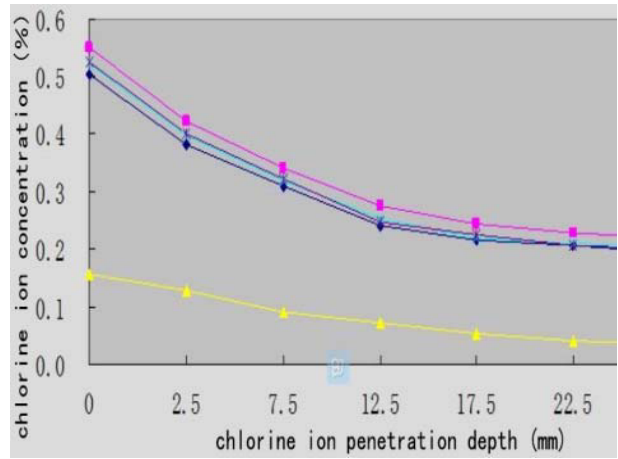

Fig.9 Relation graph between chlorine ion

concentration and penetration depth under different

service time in salt-fog atmosphere zone

It can be seen from the Fig. 8 and Fig.9 that, in marine environment at Shantou area, although concrete interior chlorine ion concentration in salt-fog atmosphere zone is significantly lower than splash zone, at the meantime, the concrete strength is higher the resistance against chlorine ion ability is greater. But overall, the chlorine ion concentration of reinforced concrete structure at each depth is proportional to the service time, with the extension of structure service time, the total chlorine ion concentration continuously increasing, but the increase rate became slowly as time, chloride ion concentration gradually become stable. Due to the concrete chloride ion concentration differ with depth, and increase with the extend of corrosion time, therefore, in this experiment, the chlorine ion diffusion model of concrete follow the Fick's second law.

Under the effect of chlorine ion erosion, carry on the curve fitting of chloride ion concentration by determining the layer depth of different service time concrete structure. The protective layer thickness of the test structure all are $30 \mathrm{~mm}$, in order to maintain a certain safety margin, taken $27.5 \mathrm{~mm}$ depth position's chloride ion concentration as the critical concentration which could cause concrete interior steel corrosion. For structures located in splash zone, matching various curve by origin 7.5 , it can be seen that exponential curve have higher fitting precision, the exponential curve expression is:

$$
t=Y e^{C / X}+Y_{0}
$$

In the formula, $\mathrm{t}$-service time; $\mathrm{C}$-concrete chloride ion concentration at $27.5 \mathrm{~mm}$ depth position.

Fitting result is $\mathrm{Y}=0.0265, \mathrm{X}=0.0407, \mathrm{Y} 0=1.9178$, shown as Fig. 10 .

For structures located in salt-fog atmosphere zone, matching various curve by origin 7.5, it also can be seen that exponential curve (2) have higher fitting precision, the fitting result is $\mathrm{Y}=4.6840, \mathrm{X}=0.0407, \mathrm{Y} 0=-4.0871$, shown as Fig. 11 . 


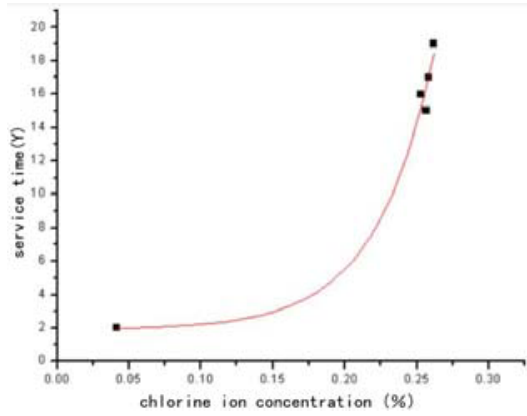

Fig.10 Relation graph between chlorine ion concentration and service time in splash zone

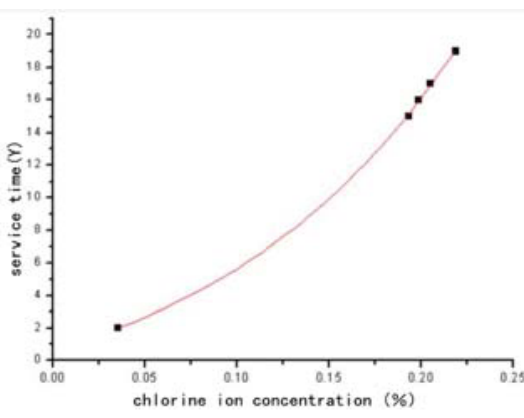

Fig.11 Relation graph between chlorine ion

concentration and service time in salt-fog atmosphere

zone

Generally define the maximum chloride ion concentration which would not cause reinforcement corrosion as the critical concentration, and the research suggests that define chloride ion concentration reach a certain value as the critical concentration that cause reinforcement corrosion. At present, in the process of designing structure working life, usually adopt the chlorine ion critical concentration of $0.06 \%$ or $0.07 \%$ concrete weight[4]. In this way, chlorine ion critical concentration which cause reinforcement corrosion can be determined according to the Table 2. Therefore, in the coastal salt-fog environment, for ready-built structure, it can direct the selection of design scheme; for existing structure, it can assist predicting the corrosion time of interior steel at different position, make maintenance timely and ensure the serviceability of structure.

\section{Conclusion}

This paper through choosing the most typical zones: the splash zone and the salt-fog atmosphere zone for sampling, determined the chloride ion concentration of each depth, carried out the comparative analysis of relative surface concrete structure chloride ion concentration change with the depth under different service time, different concrete strength and different elevation, conclude the following conclusions:

1) There are three different development trend of concrete interior chloride ion concentration at coastal salt-fog area: at the range that the distance from concrete surface is $0 \sim 12.5 \mathrm{~mm}$, with distance increase the chloride ion concentration reduce quickly and the reduction amplitude is significant; at the range that the distance from concrete surface is $12.5 \sim 22.5 \mathrm{~mm}$, with distance increase the chloride ion concentration reduction amplitude becoming mild; at the range that the distance from concrete surface exceed $22.5 \mathrm{~mm}$, chloride ion concentration gradually become stable, almost not influenced by depth change.

2) Concrete structures at the same location of coastal salt-fog area, concrete chlorine ion concentration in splash zone is significantly higher than salt-fog atmosphere zone. Meanwhile coastal concrete structure located in splash zone, the chloride ion concentration changes with the different elevation from the sea level, as the increase of elevation, the chloride ion concentration first increased to a top point and then began to gradually decrease, present the parabolic trend. For coastal concrete structure located in salt-fog atmosphere zone, the different relative position between concrete surface and sea surface has conspicuous influence on concrete interior chloride ion concentration.

3) In marine environment at coastal salt-fog area, concrete interior chlorine ion concentration in salt-fog atmosphere zone is significantly lower than splash zone, at the meantime, the concrete strength is higher the resistance against chlorine ion ability is 
greater. But overall, the chlorine ion concentration of reinforced concrete structure at each depth is proportional to the service time, with the extension of structure service time, the total chlorine ion concentration continuously increasing, but the increase rate became slowly as time, chloride ion concentration gradually become stable. Due to the concrete chloride ion concentration differ with depth, and increase with the extend of corrosion time, therefore, in this experiment, the chlorine ion diffusion model of concrete follow the Fick's second law.

4) Under the effect of chlorine ion erosion, carry on the curve fitting of chloride ion concentration by determining the layer depth of different service time concrete structure. It can be seen that exponential curve $\mathrm{t}=\mathrm{Ye}^{\mathrm{C} / \mathrm{X}}+\mathrm{Y}_{0}$ have higher fitting precision. Fitting result of splash zone is $\mathrm{Y}=0.0265, \mathrm{X}=0.0407, \mathrm{Y}_{0}=1.9178$; fitting result of splash zone is $\mathrm{Y}=4.6840$, $\mathrm{X}=0.0407, \mathrm{Y}_{0}=-4.0871$. In this way, for ready-built structure, it can direct the selection of design scheme; for existing structure, it can assist predicting the corrosion time of interior steel at different position, make maintenance timely and ensure the serviceability of structure.

\section{Acknowledgments}

This work was financially supported by the China Southern Power Grid Corp funded science and technology project (GDKJ00000030).

\section{References}

1. Xu Wei GAN, Qing-hui, TAang Qiang. Characteristics of fog and its climatic controls from 1951 to 2006 in Shantou, Guangdong province. Journal of Meteorology and Enviroment, 2008, 24(3).

2. Yao Changjian. Penetration Laws of Chloride Ions in Concrete Infrastructures at Coastal Ports. Zhejiang University, 2007

3. Liu Hongliang. Research on chloride diffusion in concrete with time-dependent coeficients and the durability analysis of concrete structures. Guangxi University, 2009

4. Zhao jun. Service life design of reinforced concrete structures exposed to chloride environment. Concrete, 2004(1). 